
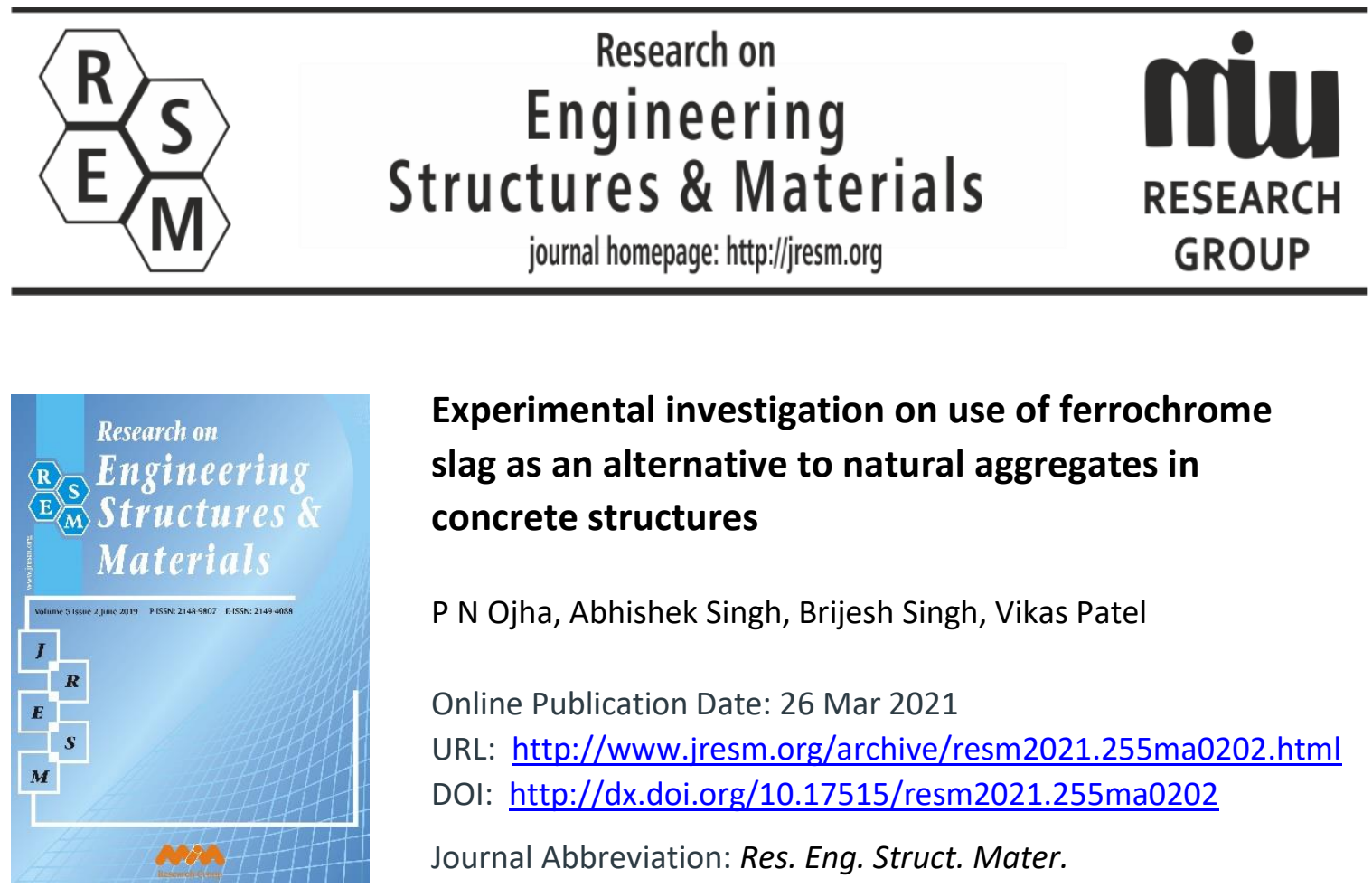

\title{
Experimental investigation on use of ferrochrome slag as an alternative to natural aggregates in concrete structures
}

P N Ojha, Abhishek Singh, Brijesh Singh, Vikas Patel

Online Publication Date: 26 Mar 2021

URL: http://www.jresm.org/archive/resm2021.255ma0202.html

DOI: http://dx.doi.org/10.17515/resm2021.255ma0202

Journal Abbreviation: Res. Eng. Struct. Mater.

\section{To cite this article}

Ojha PN, Singh A, Singh B, Patel V. Experimental investigation on use of ferrochrome slag as an alternative to natural aggregates in concrete structures. Res. Eng. Struct. Mater., 2021; $7(2): 225-244$.

\section{Disclaimer}

All the opinions and statements expressed in the papers are on the responsibility of author(s) and are not to be regarded as those of the journal of Research on Engineering Structures and Materials (RESM) organization or related parties. The publishers make no warranty, explicit or implied, or make any representation with respect to the contents of any article will be complete or accurate or up to date. The accuracy of any instructions, equations, or other information should be independently verified. The publisher and related parties shall not be liable for any loss, actions, claims, proceedings, demand or costs or damages whatsoever or howsoever caused arising directly or indirectly in connection with use of the information given in the journal or related means.

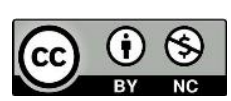

Published articles are freely available to users under the terms of Creative Commons Attribution - NonCommercial 4.0 International Public License, as currently displayed at here (the "CC BY - NC"). 


\title{
Research on Engineering Structures \& Materials
}

journal homepage: http://jresm.org

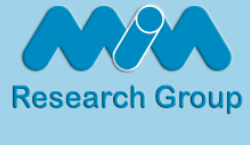

Research Article

\section{Experimental investigation on use of ferrochrome slag as an alternative to natural aggregates in concrete structures}

\author{
Parmanand N. Ojha ${ }^{\mathrm{a}}$, Abhishek Singh ${ }^{\mathrm{b}}$, Brijesh Singh"c, Vikas Patel ${ }^{\mathrm{d}}$
}

National Council for Cement and Building Materials, India

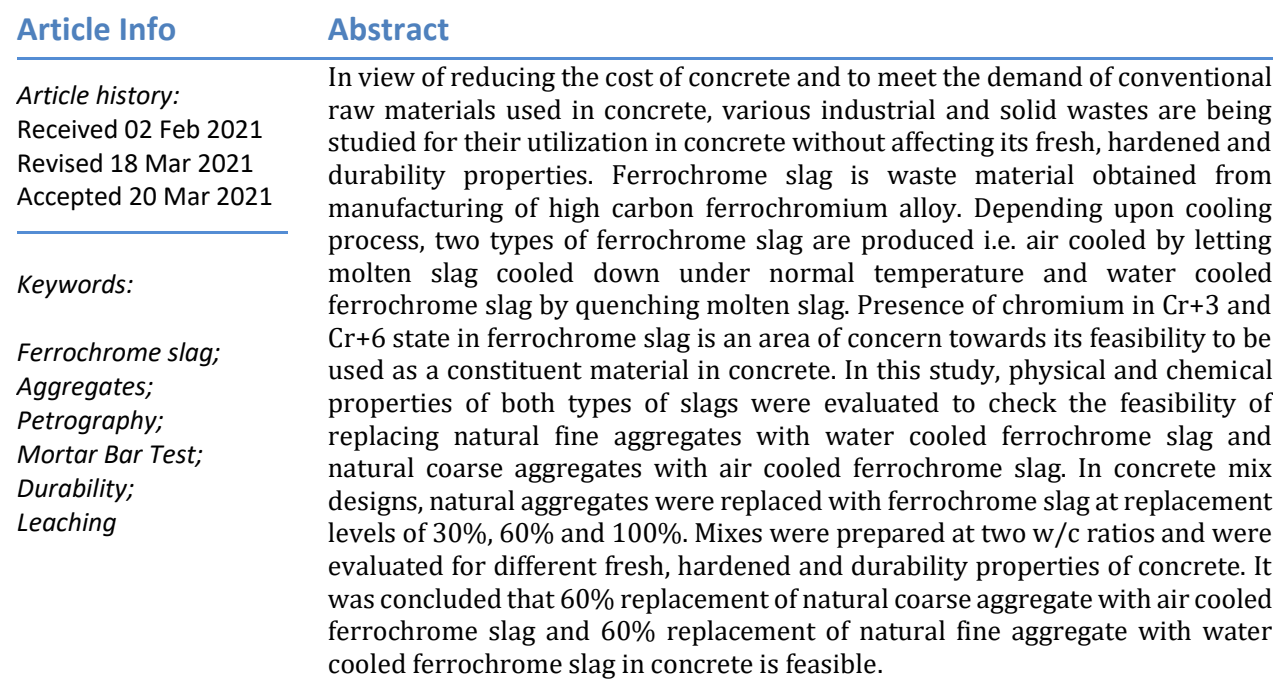

(C) 2021 MIM Research Group. All rights reserved.

\section{Introduction}

Concrete is the most commonly used structural material for majority of construction work taking place across the globe. Out of its total volume, aggregate (both coarse and fine combined) makes up for the $70 \%$ of its volume and thereby making them the principal component materials in concrete production. Rapid growth in population, urbanization and industrialization has led to huge increase in demand of housing, transportation and other infrastructural amenities which will require large amount of concrete. This has resulted in scarcity of conventional fine and coarse aggregates which are required for producing concrete. In view of reducing the cost of concrete and to meet the demand of conventional raw materials used in concrete, various industrial and solid wastes are being studied for their utilization in concrete without affecting its fresh, hardened and durability properties. The use of industrial solid waste as a partial replacement of conventional raw materials for preparation of concrete is a favorable way to reduce the environmental impact from the construction industry along with compensating the lack of natural resources and thereby reducing the demand for extraction of natural raw materials [1].

\footnotetext{
${ }^{*}$ Corresponding author: brijeshsehwagiitr96@gmail.com

a orcid.org/0000-0003-1754-4488; b orcid.org/0000-0002-2343-5934; c orcid.org/0000-0002-6512-1968;

d orcid.org/0000-0002-2251-3849

DOI: http://dx.doi.org/10.17515/resm2021.255ma0202
}

Res. Eng. Struct. Mat. Vol. 7 Iss. 2 (2021) 225-244 
The Ferrochrome slag is an important byproduct of ferrochromium industries and generated during the manufacturing of ferrochrome alloy. Ferrochrome alloy is manufactured in a submerged electric arc furnace by physiochemical process at the temperature of $1700^{\circ} \mathrm{C}$. The main constituents of ferrochrome slag are SiO2, Al2O3 and $\mathrm{MgO}$ with minor traces of ferrous/ferric oxides and $\mathrm{CaO}$. Chromium is generally present in the form of partial altered chromite and entrapped alloy. Quartzite is added as fluxing material to reduce the melting temperature of slag. The slag production is $1.1-1.6 \mathrm{t} / \mathrm{t}$ Ferrochrome alloy depending on feed materials.

Depending upon the cooling process, two types of ferrochrome slag are produced i.e. air cooled by letting the molten slag cool under normal temperature and water cooled ferrochrome slag by quenching the molten slag. Since, the particle size of air cooled ferrochrome slag is in coarser range, it can potentially be used as replacement of natural coarse aggregate in concrete. Whereas, since the particle size of water cooled ferrochrome slag lies in finer range, it can potentially be used as replacement of natural fine aggregate in concrete. However, presence of chromium as $\mathrm{Cr}+3$ which is not soluble in water (when oxidized turns into $\mathrm{Cr}+6$ ) and $\mathrm{Cr}+6$ which is soluble in water (hazardous), makes ferrochrome slag a potent threat to environment.

The Ferrochrome slag possesses physical properties similar to natural aggregates which makes it a suitable material for application in concrete as a replacement of natural aggregates. However, very limited research work and studies have been conducted to investigate presence of different forms of Chromium in ferrochrome slag and possibility of utilization of ferrochrome slag as replacement of conventional aggregates in concrete (especially reinforced cement concrete). In both water cooled and air cooled ferrochrome slag as determined by Nilamadhaba et.al [2], chromium is present in stable spinel phase and in the form of entrapped metallic granules. In molten slag, $\mathrm{Cr}$ is mainly in $\mathrm{Cr}+2$, which is not stable at room temperature and therefore solidifies in most stable oxide i.e. $\mathrm{Cr} 2 \mathrm{O} 3$ or $\mathrm{Cr}+3$ which is insoluble in water and also not expected to oxidize at atmospheric temperature to highly soluble and carcinogenic $\mathrm{Cr}+6$ form. The Chromium present in entrapped metallic granules is in dispersed state and therefore not expected to leach out when in contact with water. However, many researchers addressed the oxidation of $\mathrm{Cr}+3$ to $\mathrm{Cr}+6$ in the presence of strong oxidants which results in the possibility of slowly releasing $\mathrm{Cr}+6$ to the environment in the long run. Leachability of heavy metals is the main environmental concern due to possible impacts on human health and environmental pacts.

Lind et. al [3] investigated that "leaching tests with salt seawater and $\mathrm{pH}$ adjusted water reveal low leachability from the slag for most elements. It was also reported that in road construction, there was a low migration of particles from the slag to the underlying soil and that the leaching from the Ferrochrome slag to the groundwater was low for the elements analyzed, with the exception of potassium. Al Jabri et al. [4] investigated the combined effects of fly ash as cement replacement and ferrochrome slag as a substitute of natural aggregate. Cement was replaced with fly ash at the ratio of 10,20 , and $30 \%$ whereas coarse limestone aggregates were replaced with coarse ferrochromium aggregate at replacement levels of 25,50 , and $75 \%$. The results from the study revealed that inclusion of ferrochromium aggregates led to increase in the strength of concrete and also the abrasive wear resistance while it has negligible influence on the porosity and water absorption of concrete.

Panda et.al [5] investigated the environmental and mechanical properties of concrete containing ferrochrome slag. The concrete showed increased strength in comparison to control sample. The standard leaching experimental results showed that the leachable chromium remains well immobilized in the cement and concrete matrix with very low to non-detectable level of chromium leaching. Sathwik et. al [6] investigated the utilization of 
ferrochrome slag as replacement of coarse aggregate in concrete. They conducted the study on M50 grade of concrete. Their studies revealed that in concrete made with up to $75 \%$ replacement of natural aggregates with ferrochrome slag, the compressive and flexural strength was found comparable with that of the control sample. Zyranov et. al [7] investigated the possibility of low carbon ferrochrome slag into a dry slag and further recycling it into commercial product. Their study concluded that the strength of concrete under normal condition is less than the strength of concrete under steam curing as high temperature activates the process of slag hydration.

In view of the above mentioned studies, it becomes imperative to conduct studies and evaluate the performance of concrete mixes containing water and air cooled ferrochrome slag as replacement of natural aggregates in concrete and compare their performance with corresponding control concrete mixes made with 100\% natural aggregates in terms of different fresh, hardened and especially durability properties of concrete, as very limited studies has been conducted on the durability parameters of concrete made with ferrochrome slag as a replacement of natural aggregates.

\section{The Effect of Factors on Shear Force}

In this study, Ferrochrome slag (both water cooled and air cooled) aggregates were evaluated for different physical characteristics as per IS: 2386 [8] (as applicable for manufactured sand and manufactured coarse aggregates). Both water and air cooled ferrochrome slag samples were subjected to chemical analysis as per IS 4032 [9] for evaluation of loss on Ignition, major constituents (Cr203, Al203, Fe203, CaO, SiO2, reactive silica and $\mathrm{MgO}$ ) and minor constituents ( $\mathrm{Na} 2 \mathrm{O}, \mathrm{K} 2 \mathrm{O}, \mathrm{SO} 3, \mathrm{Cl}-$, TiO2 etc.). Total alkali content as $\mathrm{Na} 20$ equivalent, total sulphate content as $\mathrm{SO}$, acid and water soluble chloride content and total sulphur as S. Elemental analysis and leaching study as per Toxicity characteristic leaching procedure (TCLP) as per ASTM D5233 [10] for heavy metals was carried out for both ferrochrome slag samples. Both air and water cooled ferrochrome slag aggregates were evaluated for Alkali Silica reactivity using accelerated and long term mortar bar test. Other concrete making materials such as cement, natural aggregate and admixture were meeting the criteria as mentioned in relevant Indian Standards.

Two control concrete mixes were prepared using Ordinary Portland Cement (OPC) along with $100 \%$ natural fine aggregates and $100 \%$ natural coarse aggregates at two different water-cement ratios of 0.65 and 0.40 . Then, mixes were prepared by replacing natural fine aggregates with water cooled ferrochrome slag at 30, 60 and $100 \%$ along with $100 \%$ natural coarse aggregates at both the water cement ratios. Further, mixes were prepared by replacing natural coarse aggregate with air cooled ferrochrome slag at 30, 60 and 100\% along with $100 \%$ natural fine aggregates at both the water cement ratios. Thus, a total number of 14 concrete mixes were prepared. All the mixes were studied for fresh properties of concrete such as workability (in terms of slump at 30,60, 90 and 120 minutes) and air content of concrete as per IS: 1199 [11]. Further, mixes were evaluated for different mechanical properties such as compressive strength, flexural strength, split tensile strength, density, drying shrinkage of concrete and modulus of elasticity of concrete at various ages. Mixes were also studied for different durability properties of concrete tests such as Rapid Chloride ion penetrability test (RCPT), Sulphate expansion test, Chloride migration test, accelerated carbonation test and sorptivity test. 


\section{Properties of Air Cooled Ferrochrome Slag and Water Cooled Ferrochrome Slag}

\subsection{Physical Properties of Ferrochrome Slag}

Sieve analysis of water cooled ferrochrome slag $(<4.75 \mathrm{~mm})$ and air Cooled Ferrochrome slag (20 mm and $10 \mathrm{~mm}$ ) samples were carried out as per IS 383:2016 [12] and the results are given in Table 1.

Table 1. Sieve analysis of ferrochrome slag samples

\begin{tabular}{cccc}
\hline IS Sieve Size & $\begin{array}{c}\text { Water Cooled } \\
\text { Ferrochrome slag } \\
(<4.75 \mathrm{~mm}) \\
\text { \% Passing }\end{array}$ & $\begin{array}{c}\text { Air Cooled } \\
\text { Ferrochrome slag, } \\
20 \mathrm{~mm}, \% \text { Passing }\end{array}$ & $\begin{array}{c}\text { Air Cooled } \\
\text { Ferrochrome slag, } \\
\text { 10mm, \% Passing }\end{array}$ \\
\hline $40 \mathrm{~mm}$ & - & 100 & - \\
$20 \mathrm{~mm}$ & - & 100 & - \\
$12.5 \mathrm{~mm}$ & - & - & 100 \\
$10 \mathrm{~mm}$ & 100 & 28 & 100 \\
$4.75 \mathrm{~mm}$ & 100 & 1 & 23 \\
$2.36 \mathrm{~mm}$ & 98 & - & - \\
$1.18 \mathrm{~mm}$ & 79 & - & - \\
$600 \mu \mathrm{m}$ & 46 & - & - \\
$300 \mu \mathrm{m}$ & 28 & - & - \\
$150 \mu \mathrm{m}$ & 15 & - & \\
\hline
\end{tabular}

The physical properties of Ferrochrome slag samples are given in Table 2 below. The physical properties of water cooled and air cooled ferrochrome slag meets the various requirements of IS: 383-2016. The specific gravity of slag samples was observed to be higher than that of natural aggregates. Water absorption and material finer than $75 \mu \mathrm{m}$ were found to be comparable with natural aggregates. The water cooled ferrochrome slag lies in zone 2 of grading as per IS: 383-2016. The low values of abrasion, crushing and impact reflects the stronger nature of air cooled ferrochrome slag.

Table 2. Physical properties of ferrochrome slag samples

\begin{tabular}{cccc}
\hline Test Carried out & $\begin{array}{c}\text { Water Cooled } \\
\text { Ferrochrome } \\
\text { slag } \\
(<4.75 \mathrm{~mm})\end{array}$ & $\begin{array}{c}\text { Air Cooled } \\
\text { Ferrochrome } \\
\text { slag, 20mm }\end{array}$ & $\begin{array}{c}\text { Air Cooled } \\
\text { Ferrochrome } \\
\text { slag, 10mm }\end{array}$ \\
\hline Specific gravity & 2.87 & 2.99 & 2.98 \\
Water absorption, \% & 0.74 & 0.33 & 0.31 \\
Material finer than 75 $\mu \mathrm{m} \%$ (wet & 3.97 & 0.10 & 0.1 \\
sieving) & 2.68 & 1.28 & 1.91 \\
Soundness , MgSO4 \% & Nil & Nil & Nil \\
Organic impurities \% & Nil & Nil & Nil \\
Clay Lumps \% & Nil & Nil & Nil \\
Total deleterious material, \% & 1.09 & 1.61 & 1.43 \\
(excluding coal \& lignite) & 1.21 & 1.71 & 1.56 \\
Loose Bulk Density, Kg/lit & - & 14 & - \\
Compacted Bulk Density, Kg/lit & - & 19 & - \\
Abrasion value & - & 15 & - \\
Crushing Value & & & \\
Impact Value & &
\end{tabular}




\subsection{Chemical Properties of Ferrochrome Slag Samples}

Both type of ferrochrome slag samples (water cooled and air cooled) were studied for several chemical parameters as per IS 4032. The chemical properties of ferrochrome slag samples are tabulated in Table 3 below.

Table 3. Chemical properties of ferrochrome slag samples

\begin{tabular}{ccc}
\hline Test Carried out & $\begin{array}{c}\text { Water Cooled } \\
\text { Ferrochrome slag } \\
(<4.75 \mathrm{~mm}), \%\end{array}$ & $\begin{array}{c}\text { Air Cooled } \\
\text { Ferrochrome slag, } \\
(>4.75 \mathrm{~mm}), \%\end{array}$ \\
\hline Gain on Ignition, \% & +1.51 & +0.93 \\
Silica & 25.73 & 31.54 \\
Iron Oxide & 3.59 & 5.23 \\
Alumina & 35.3 & 28.67 \\
Calcium Oxide & 2.8 & 3.68 \\
Magnesium Oxide & 22.36 & 19.22 \\
Sulphuric Anhydride & 0.12 & 0.06 \\
Chloride & 0.015 & 0.01 \\
Alkalis (as Na20eq) & 0.23 & 0.55 \\
Titanium Dioxide & 1.06 & 1.44 \\
Total Sulphur & 0.25 & 0.44 \\
\hline
\end{tabular}

As per IS 383: 2016, the prescribed limit of total alkali content is $0.3 \%$. The observed value of alkalis equivalent is $0.23 \%$ in case of water cooled ferrochrome slag which lies within the limit specified. However, the value obtained in case of air cooled ferrochrome slag is higher than the prescribed limit. The observed values of chloride content, calcium oxide, iron oxide and total Sulphur are well within the limits specified in IS 383: 2016.

\subsection{Elemental Analysis of Ferrochrome Slag Samples}

Both water cooled and air cooled ferrochrome slag samples were subjected to elemental analysis. The results of elemental analysis of ferrochrome slag samples are tabulated in Table 4 below.

Table 11 of IS: 383-2016 quotes limits for environmental safety and quality standards for using iron, steel and copper slag aggregates. The values obtained for cadmium, lead, selenium and hexavalent chromium are within limits. 
Table 4. Results of elemental analysis of ferrochrome slag samples

\begin{tabular}{ccc}
\hline Element & $\begin{array}{c}\text { Water Cooled Ferrochrome } \\
\text { slag }(<4.75 \mathrm{~mm}), \%\end{array}$ & $\begin{array}{c}\text { Air Cooled Ferrochrome } \\
\text { slag, } \\
(>4.75 \mathrm{~mm}), \%\end{array}$ \\
\hline Barium & 0.027 & 0.098 \\
Beryllium & 0.001 & 0.0005 \\
Bismuth & Below detection Limit & Below detection Limit \\
Cadmium & 0.002 & 0.001 \\
Cobalt & 0.012 & 0.012 \\
Chromium & 8 & 8.86 \\
Copper & 0.175 & 0.42 \\
Gallium & Below Detection Limit & Below Detection Limit \\
Manganese & 0.219 & 0.185 \\
Molybednum & 0.011 & 0.008 \\
Nickel & 0.032 & 0.04 \\
Lead & 0.013 & 0.008 \\
Selenium & 0.088 & Below Detection Limit \\
Strontium & Below Detection Limit & 0.008 \\
Tellurium & Below Detection Limit & Below Detection Limit \\
Thallium & Below Detection Limit & Below Detection Limit \\
Zinc & 0.029 & 0.061 \\
Vanadium & 0.012 & 0.013 \\
Chromium, Cr+3 & - & - \\
Chromium, Cr+6 & 0.0002 & 0.0003 \\
\hline
\end{tabular}

\subsection{Leaching Study for Heavy Metals on Ferrochrome Slag Samples}

Leaching study on air and water cooled ferrochrome slag was conducted as per TCLP procedure. The results of concentration of heavy metals in slag sample is tabulated in Table 5 below.

Table 5. Results of leaching study on ferrochrome slag and natural aggregates

\begin{tabular}{ccccc}
\hline Sl No. & Constituents & $\begin{array}{c}\text { Water cooled } \\
\text { FS Slag FA }\end{array}$ & $\begin{array}{c}\text { Air-cooled FS } \\
\text { Slag CA }\end{array}$ & $\begin{array}{c}\text { Limits as per } \\
\text { TCLP procedure }\end{array}$ \\
\hline 1 & Chromium & 0.486 & 0.727 & 5 \\
2 & Copper & 0.005 & $*$ BDL & 25 \\
3 & Manganese & 1.298 & 1.215 & 10 \\
4 & Nickel & 0.831 & 0.774 & 20 \\
5 & Lead & 0.020 & BDL & 5 \\
6 & Zinc & 0.208 & 0.209 & 250 \\
7 & Iron & 45.37 & 53.93 & - \\
8 & Titanium & 0.012 & 0.011 & - \\
\hline
\end{tabular}

As per the leachable concentration limits given in ministry of environment [13], forest and climate change guidelines, the observed values are lower than the prescribed limits. 


\subsection{Petrographic Examination of Ferrochrome slag Sample}

Air cooled and water cooled ferrochrome slag samples were subjected to petrographic examination and their results are as mentioned below in sub sections 3.5.1 and 3.5.2.

\subsubsection{Petrographic Examination of Air Cooled Ferrochrome Slag}

This is a medium grained textured partially weathered random sample of the coarse aggregate. The major mineral constituents are spinel, olivine and clinopyroxene. Accessory minerals are quartz and iron oxide. Micro globular glass grains with corroded margins present as clusters are uniformly distributed in the sample. Majority of glass grains are in the size range of $7 \mu \mathrm{m}$ to $53 \mu \mathrm{m}$. Subhedral to euhedral spinel grains with sharp grain margins are also uniformly distributed in the aggregate. Euhedral olivine grains with sharp grain margins are partially fractured and shattered. Grain size of olivine varies from $55 \mu \mathrm{m}$ to $1052 \mu \mathrm{m}$ with an average of $502 \mu \mathrm{m}$. Subhedral to anhedral clinopyroxene grains with corroded margins are fractured and shattered. Subhedral quartz grains with sharp grain margins are randomly distributed in the sample. Anhedral iron oxide grains are also randomly distributed in the sample. Microphotographs are given in Fig 1.

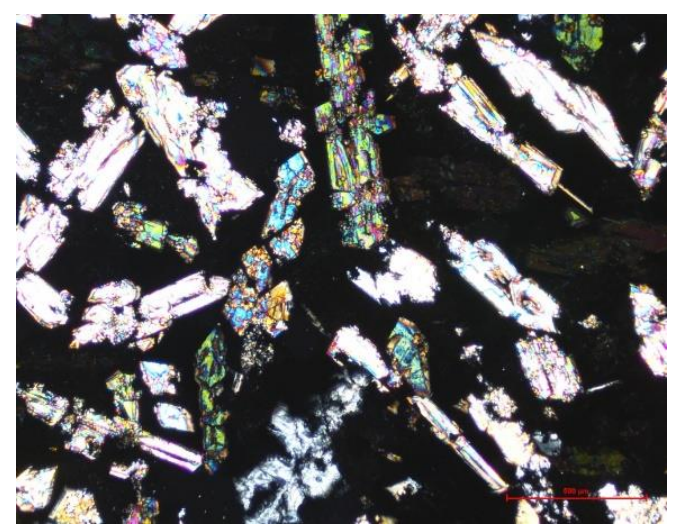

Fig. 1 Micrograph of air cooled Ferrochrome slag using optical microscope showing distribution of mineral grains in the sample (5x, x-nicols)

\subsubsection{Petrographic Examination of Water Cooled Ferrochrome Slag}

This is a fine grained textured partially weathered random sample of the fine aggregate. The predominant phase in the sample is glass. Subhedral to anhedral glass grains with sharp grain margins are uniformly distributed in the sample. Few elongated shaped glass grains are also observed in the fine aggregate. Grain size of glass varies from $15 \mu \mathrm{m}$ to $408 \mu \mathrm{m}$ with an average of $167 \mu \mathrm{m}$. Majority of glass grains are in the size range of $150 \mu \mathrm{m}$ to $170 \mu \mathrm{m}$. Other mineral phases are quartz, orthoclase-feldspar, muscovite and iron oxide. Subhedral quartz grains with sharp grain margins are randomly distributed in the sample. Majority of quartz grains are in the size range of $100 \mu \mathrm{m}$ to $140 \mu \mathrm{m}$. Subhedral orthoclase grains with rounded grain margins are also randomly distributed in the sample. Needle to lath shaped muscovite grains are mostly fresh in nature. Anhedral to subhedral iron oxide grains with corroded margins are uniformly distributed in the sample. Microphotographs are given in Fig 2. 


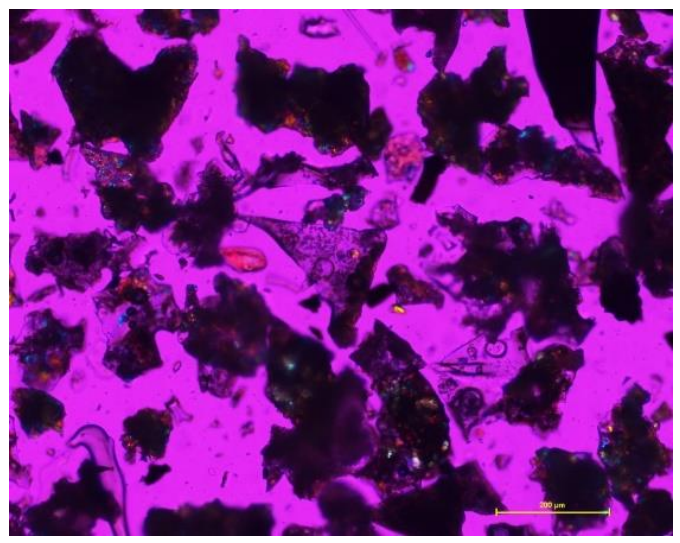

Fig. 2 Micrograph of water cooled ferrochrome slag using optical microscope showing distribution of mineral grains in the sample (5x, $x$-nicols)

\subsection{Accelerated Mortar Bar Test}

Accelerated mortar bar test was conducted on both water and air cooled ferrochrome slag aggregates as per ASTM C-1260 [14] for following compositions:

- $0 \%$ replacement of natural aggregates with ferrochrome slag

- $100 \%$ replacement of natural sand with water cooled ferrochrome slag samples.

- $100 \%$ replacement of natural coarse aggregate with air cooled ferrochrome slag samples.

The accelerated mortar-bar test as per ASTM 1260 consists of preparing mortar-bar in the same way as for conventional tests as per IS: 2386 i.e., by proportioning one part of Ordinary Portland Cement (OPC) to 2.25 parts of graded aggregates by mass, a fixed water to cement ratio of 0.47 . The sample after 24 -hours was de-moulded and then cured in hot water at $80^{\circ} \mathrm{C}$ for 24 -hours. Finally, the specimen was stored in $1 \mathrm{~N} \mathrm{NaOH}$ solutions at $80^{\circ} \mathrm{C}$ for 14 days. The length change observations were taken in hot condition i.e., within $15+5$ seconds after taking out from the solution. The samples were stored in plastic containers. As per ASTM criteria, the aggregate showing expansions less than $0.10 \%$ at 16 days after casting are classified as innocuous, whereas the aggregates showing more than $0.20 \%$ expansion are classified as potentially reactive. For aggregates showing expansion between $0.10 \%$ and $0.20 \%$, the results are to be supported by other tests. Test results are given in Table 6. For all types of compositions, aggregates showed innocuous behaviour as expansion in all the cases were reported below $0.10 \%$.

Table 6. Accelerated mortar bar test (ASTM C1260)

\begin{tabular}{cccc}
\hline S.No. & Sample Type & $\begin{array}{c}\text { 1N NaOH 800C } \\
\text { 14 Day Expansion } \\
\%\end{array}$ & Remarks \\
\hline 1 & Fine Aggregate (0\% replacement) & 0.07 & innocuous \\
2 & Fine Aggregate (100\% replacement) & 0.03 & innocuous \\
3 & Coarse Aggregate (100\% & 0.09 & innocuous \\
\hline
\end{tabular}




\subsection{Mortar-Bar Test}

Mortar-bar test was conducted at normal regime of $380 \mathrm{C}$ and accelerated regime of $600 \mathrm{C}$ as per IS: 2386 . The test at $380 \mathrm{C}$ was conducted to bring out the effect of metastable silica minerals present in aggregates, if any, and tests at $600 \mathrm{C}$ was conducted to bring out the effect of slowly reactive strained quartz type of aggregates. The test was conducted using two reference OPC samples i.e. OPC- 1 having alkali content (Na2O eq.) of $1.56 \%$ and OPC2 having alkali content of $0.59 \%$. The results of the mortar-bar tests are presented in Fig. 3 and 4. On perusal of mortar bar test results in Fig. 3 and 4, it can be seen that the expansions are within the permissible limits of $0.05 \%$ at 90 days and $0.06 \%$ at 180 days with all combinations. Therefore, ferrochrome aggregate samples were classified as innocuous as per IS: 2386.

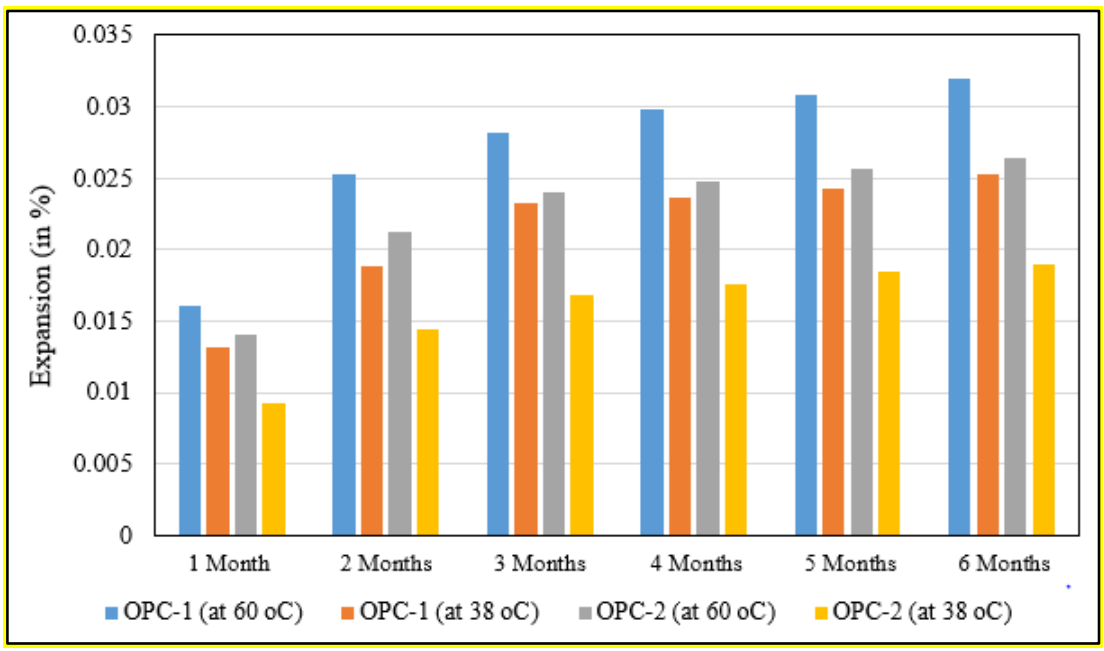

Fig. 3 Alkali aggregate reactivity as per IS: 2386 part VII for water cooled ferrochrome slag as $100 \%$ replacement of natural sand

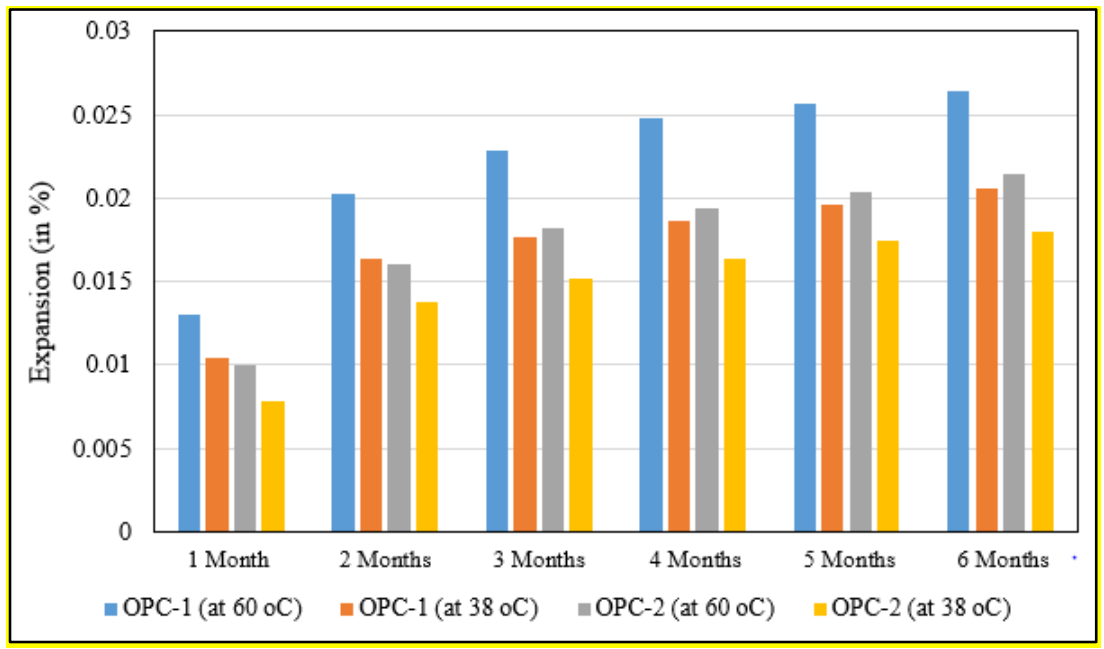

Fig. 4 Alkali aggregate reactivity as per IS: 2386 part VII for air cooled ferrochrome slag as $100 \%$ replacement of natural coarse aggregate. 


\section{Studies on Fresh, Hardened and Durability Properties of Concrete Mixes}

\subsection{Concrete Mixes Containing Water Cooled Ferrochrome Slag as Replacement of Natural Fine Aggregate}

Two control concrete mixes (M4 and M0) were prepared using OPC along with $100 \%$ natural fine aggregates and $100 \%$ natural coarse aggregates at two water-cement ratios of 0.65 and 0.40 . Then, mixes were prepared by replacing natural fine aggregate with water cooled ferrochrome slag at 30, 60 and 100\% along with 100\% natural coarse aggregates at both the water cement ratios

Therefore, a total of 8 mix designs ( 2 no. of control mixes $+3 \times 2=6$ number of mixes containing water cooled ferrochrome slag as fine aggregate) were carried out. The concrete mixes were designed for initial slump value of about $150 \mathrm{~mm}$. Mix design details of concrete mixes are tabulated in Table 7.

Table 7. Concrete mix design details of mixes containing water cooled ferrochrome slag as replacement of natural fine aggregate

\begin{tabular}{cccccc}
\hline S. No. & Mix & $\begin{array}{c}\text { Ferrochrome } \\
\text { slag as fine } \\
\text { Aggregates (\%) }\end{array}$ & $\begin{array}{c}\text { Cement } \\
(\mathrm{Kg} / \mathrm{m} 3)\end{array}$ & $\begin{array}{c}\text { Water } \\
(\mathrm{Kg} / \mathrm{m} 3)\end{array}$ & $\begin{array}{c}\text { Ferrochrome slag } \\
\text { as fine } \\
\text { aggregates } \\
(\mathrm{Kg} / \mathrm{m} 3)\end{array}$ \\
\hline 1 & M0 & 0 & 300 & 195 & 0 \\
2 & M1 & 30 & 300 & 195 & 287 \\
3 & M2 & 60 & 300 & 195 & 573 \\
4 & M3 & 100 & 300 & 195 & 957 \\
5 & M4 & 0 & 425 & 170 & 0 \\
6 & M5 & 30 & 425 & 170 & 254 \\
7 & M6 & 60 & 425 & 170 & 507 \\
8 & M7 & 100 & 425 & 170 & 847 \\
\hline
\end{tabular}

Table 7. (Con.) Concrete mix design details of mixes containing water cooled ferrochrome slag as replacement of natural fine aggregate

\begin{tabular}{ccccc}
\hline S. No. & $\begin{array}{c}\text { Natural Fine } \\
\text { Aggregate } \\
(\mathrm{Kg} / \mathrm{m} 3)\end{array}$ & $\begin{array}{c}\text { Natural Coarse } \\
\text { Aggregate } \\
(10 \mathrm{~mm}) \\
(\mathrm{Kg} / \mathrm{m} 3)\end{array}$ & $\begin{array}{c}\text { Natural Coarse } \\
\text { Aggregate } \\
(20 \mathrm{~mm}) \\
(\mathrm{Kg} / \mathrm{m} 3)\end{array}$ & $\begin{array}{c}\text { Admix } \\
(\%)\end{array}$ \\
\hline 1 & 874 & 414 & 623 & 0 \\
2 & 611 & 413 & 622 & 0.2 \\
3 & 349 & 413 & 621 & 0.7 \\
4 & 0 & 413 & 622 & 0.2 \\
5 & 773 & 439 & 661 & 0.2 \\
6 & 541 & 439 & 661 & 0.3 \\
7 & 309 & 439 & 660 & 0.5 \\
8 & 0 & 439 & 661 & 0.2 \\
\hline
\end{tabular}

\subsubsection{Fresh Concrete Properties}

Fresh concrete properties such as workability (in terms of slump at 0 minutes, 30 minutes, 60 minutes and 120 minutes after preparation of mix) and air content were evaluated for all the 8 mixes and test results are given in Table 8. 
Table 8. Fresh concrete properties of mixes containing water cooled Ferrochrome slag as replacement of natural fine aggregate

$\begin{array}{lcc}\text { S. No W/c Ratio } & \text { Mix ID } & \begin{array}{c}\text { Ferrochrome slag as fine } \\ \text { Aggregates (\%) }\end{array}\end{array}$

\begin{tabular}{lcccc}
\hline 1 & 0.65 & M0 & 0 & 100 \\
2 & 0.65 & M1 & 30 & 70 \\
3 & 0.65 & M2 & 60 & 40 \\
4 & 0.65 & M3 & 100 & 0 \\
5 & 0.4 & M4 & 0 & 100 \\
6 & 0.4 & M5 & 30 & 70 \\
7 & 0.4 & M6 & 60 & 40 \\
8 & 0.4 & M7 & 100 & 0 \\
\hline
\end{tabular}

Table 8. (Con.) Fresh concrete properties of mixes containing water cooled ferrochrome slag as replacement of natural fine aggregate

\begin{tabular}{ccccccc}
\hline \multirow{2}{*}{ S. No } & \multicolumn{4}{c}{ Workability of concrete $(\mathrm{mm}):$} & \multirow{2}{*}{$\begin{array}{c}\text { Air } \\
\text { Content, } \\
\%\end{array}$} & Remarks \\
\cline { 2 - 5 } & 0 Min & 30 Min & 60 Min & 120 Min & & \\
\hline 1 & 145 & 135 & 125 & 100 & 1.8 & Homogeneous \\
2 & 150 & 120 & 100 & 55 & 1.9 & mix \\
3 & 160 & 110 & 85 & 30 & 2 & Segregation \\
4 & 140 & 120 & 90 & 40 & 2.1 & and bleeding \\
5 & 150 & 140 & 120 & 90 & 1.7 & Homogeneous \\
6 & 150 & 110 & 80 & 40 & 1.9 & mix \\
7 & 145 & 100 & 60 & 30 & 2.1 & Segregation \\
8 & 150 & 110 & 80 & 40 & 2.4 & and bleeding \\
\hline
\end{tabular}

Concrete mixes containing Ferrochrome slag showed significantly higher slump loss after 60 and 120 minutes in comparison to the control concrete mixes. Air content of all 8 mixes were similar and comparable (around 2\%). It was observed that when replacement of natural coarse aggregate with air cooled ferrochrome slag goes beyond $60 \%$, mixes showed signs of segregation and bleeding due to high specific gravity of ferrochrome slag.

\subsubsection{Hardened Concrete Properties}

Hardened concrete properties were evaluated for the eight concrete mixes. Compressive strength test was conducted on concrete cubes $(150 \mathrm{~mm} \times 150 \mathrm{~mm} \times 150 \mathrm{~mm})$ as per IS: 516 [15]. Flexural strength test was conducted on concrete beam (size $500 \mathrm{~mm} \times 100 \mathrm{~mm} \times$ $100 \mathrm{~mm}$ ) as per IS: 516 . Split strength test and Modulus of Elasticity were conducted on concrete cylinder (150mm diameter and 300mm height) as per IS:5816 [16] and IS:516 respectively. Drying shrinkage test was conducted on concrete beam (75 x 75 x $300 \mathrm{~mm})$ as per IS:1199. The test results are in Table 9. 
Table 9. Hardened concrete properties containing of mixes containing water cooled ferrochrome slag as replacement of natural fine aggregate

\begin{tabular}{|c|c|c|c|c|c|c|c|c|}
\hline \multirow[t]{2}{*}{$\mathrm{W} / \mathrm{c}$} & \multirow{2}{*}{$\begin{array}{c}\text { Mix } \\
\text { ID }\end{array}$} & \multirow{2}{*}{$\begin{array}{l}\text { Ferrochrome } \\
\text { slag as fine } \\
\text { Aggregates (\%) }\end{array}$} & \multicolumn{4}{|c|}{ Compressive Strength, $\mathrm{MPa}$} & \multicolumn{2}{|c|}{$\begin{array}{c}\text { Flexural } \\
\text { Strength, } \\
\mathrm{MPa}\end{array}$} \\
\hline & & & $\begin{array}{c}1 \\
\text { Day }\end{array}$ & $\begin{array}{c}3 \\
\text { Day }\end{array}$ & $\begin{array}{c}7 \\
\text { Day }\end{array}$ & 28 Day & $\begin{array}{c}7 \\
\text { Day }\end{array}$ & $\begin{array}{c}28 \\
\text { Day }\end{array}$ \\
\hline 0.65 & M0 & 0 & 4.54 & 12.5 & 18.1 & 26.22 & 4.07 & 5.05 \\
\hline 0.65 & M1 & 30 & 6.33 & 14.5 & 20.2 & 30.14 & 4.4 & 5.3 \\
\hline 0.65 & M2 & 60 & 7.38 & 16.5 & 22.95 & 38.05 & 5.07 & 5.37 \\
\hline 0.65 & M3 & 100 & 8.67 & 18.8 & 24.46 & 41.89 & 5.45 & 6.01 \\
\hline 0.4 & M4 & 0 & 15.95 & 32 & 41.86 & 49.79 & 6.4 & 8.07 \\
\hline 0.4 & M5 & 30 & 19.05 & 27.2 & 43.01 & 46.75 & 6.37 & 9.77 \\
\hline 0.4 & M6 & 60 & 20.84 & 29.3 & 42.89 & 53.08 & 7.17 & 10.3 \\
\hline 0.4 & M7 & 100 & 23.76 & 27.8 & 44.78 & 56.89 & 8.5 & 11.4 \\
\hline
\end{tabular}

Table 9. (Con.) Hardened concrete properties containing of mixes containing water cooled ferrochrome slag as replacement of $n$ atural fine aggregate

\begin{tabular}{|c|c|c|c|c|c|}
\hline $\mathrm{W} / \mathrm{c}$ & Mix ID & $\begin{array}{c}\text { Split } \\
\text { Tensile } \\
\text { Strength, } \\
\mathrm{MPa}\end{array}$ & $\begin{array}{c}\text { Dry Density } \\
\mathrm{Kg} / \mathrm{m} 3\end{array}$ & $\begin{array}{c}\text { Drying } \\
\text { Shrinkage }\end{array}$ & $\begin{array}{c}\text { MOE } \\
(\mathrm{N} / \mathrm{mm} 2)\end{array}$ \\
\hline & & $\begin{array}{l}28 \\
\text { Day }\end{array}$ & $\begin{array}{c}28 \\
\text { Day }\end{array}$ & $\begin{array}{c}28 \\
\text { Day }\end{array}$ & $\begin{array}{c}28 \\
\text { Day }\end{array}$ \\
\hline 0.65 & M0 & 2.42 & 2450 & 0.0171 & 28204 \\
\hline 0.65 & M1 & 2.67 & 2470 & 0.0168 & 30651 \\
\hline 0.65 & M2 & 2.72 & 2550 & 0.0164 & 32982 \\
\hline 0.65 & M3 & 3.21 & 2502 & 0.0179 & 34876 \\
\hline 0.4 & M4 & 4.51 & 2478 & 0.0191 & 37144 \\
\hline 0.4 & M5 & 4.75 & 2494 & 0.018 & 38013 \\
\hline 0.4 & M6 & 5.1 & 2520 & 0.0175 & 38885 \\
\hline 0.4 & M7 & 5.26 & 2560 & 0.0173 & 40016 \\
\hline
\end{tabular}

Compressive, flexural and split tensile strength at age of 28 days for experimental mixes (containing water cooled ferrochrome slag as replacement of fine aggregates) at both $\mathrm{w} / \mathrm{c}$ were found to be either higher or comparable to their control mix. Due to higher specific gravity of ferrochrome slag, dry density of the concrete mixes containing water cooled ferrochrome slag were higher than control mixes. The drying shrinkage values for all the concrete mixes were found satisfactory and comparable with their corresponding control mixes. Modulus of Elasticity (MOE) of the concrete mixes containing ferrochrome slag as 
replacement of natural fine aggregates were found to be either higher or comparable to corresponding control mixes.

\subsubsection{Durability Properties of Concrete mixes}

Durability parameters of concrete such as Rapid Chloride ion penetrability test (RCPT) as per ASTM C-1202 [17], Sulphate expansion test as per ASTM C-1012 [18], Chloride migration test as per NT Build 492 [19], accelerated carbonation test as per ISO 1920 part 12 [20] and sorptivity test as per ASTM 1585 [21] were evaluated for all the eight concrete mixes. Test results are presented in Table 10.

Table 10. Durability properties of concrete mixes containing water cooled ferrochrome slag as replacement of natural fine aggregate

\begin{tabular}{|c|c|c|c|c|c|c|}
\hline \multirow[t]{2}{*}{$\mathrm{W} / \mathrm{c}$} & \multirow[t]{2}{*}{ Mix ID } & \multirow{2}{*}{$\begin{array}{c}\text { Ferrochrome } \\
\text { slag as fine } \\
\text { Aggregates } \\
(\%) \\
\end{array}$} & \multirow{2}{*}{$\begin{array}{c}\begin{array}{c}\text { RCPT, } \\
\text { Coulomb }\end{array} \\
28 \text { Day }\end{array}$} & \multicolumn{3}{|c|}{$\begin{array}{c}\text { Chloride Migration, NT Build } \\
\text { Diffusion coefficient (x 10-12 } \\
\mathrm{m} 2 / \mathrm{s} \text { ) }\end{array}$} \\
\hline & & & & 28 Day & 56 Day & 90 Day \\
\hline 0.65 & M0 & 0 & 3542 & 8.31 & 6.99 & 3.34 \\
\hline 0.65 & M1 & 30 & 3133 & 7.49 & 5.42 & 3.21 \\
\hline 0.65 & M2 & 60 & 3268 & 6.61 & 4.76 & 3.05 \\
\hline 0.65 & M3 & 100 & 2255 & 3.44 & 4.12 & 2.68 \\
\hline 0.4 & M4 & 0 & 1525 & 7.49 & 5.56 & 3.65 \\
\hline 0.4 & M5 & 30 & 1862 & 8.13 & 4.73 & 3.55 \\
\hline 0.4 & M6 & 60 & 1375 & 6.78 & 4.1 & 3.21 \\
\hline 0.4 & M7 & 100 & 1378 & 4.64 & 3.56 & 2.87 \\
\hline
\end{tabular}

Table 10. (Con.) Durability properties of concrete mixes containing water cooled ferrochrome slag as replacement of natural fine aggregate

\begin{tabular}{cccccccc}
\hline \multirow{2}{*}{ W/c } & \multirow{2}{*}{ Mix ID } & \multicolumn{2}{c}{ Sulphate expansion (\%) } & Carbonation & \multicolumn{2}{c}{ Sorptivity } \\
& & 28 Day & 56 Day & 90 Day & Depth, mm & Initial & Secondary \\
\hline 0.65 & M0 & 0.002 & 0.006 & 0.008 & 8.74 & 0.0057 & 0.0024 \\
0.65 & M1 & 0.003 & 0.005 & 0.007 & 7.33 & 0.0080 & 0.0028 \\
0.65 & M2 & 0.003 & 0.006 & 0.007 & 7.50 & 0.0062 & 0.0030 \\
0.65 & M3 & 0.002 & 0.005 & 0.009 & 7.10 & 0.0070 & 0.0038 \\
0.4 & M4 & 0.003 & 0.006 & 0.009 & Nil & 0.0032 & 0.0008 \\
0.4 & M5 & 0.003 & 0.005 & 0.007 & Nil & 0.0038 & 0.0009 \\
0.4 & M6 & 0.002 & 0.007 & 0.009 & Nil & 0.0005 & 0.0002 \\
0.4 & M7 & 0.004 & 0.006 & 0.008 & Nil & 0.0010 & 0.0006 \\
\hline
\end{tabular}

In case of RCPT, it was observed that experimental mixes containing water cooled ferrochrome slag as replacement of natural sand show comparable performance to corresponding control concrete mixes. All the mixes having w/c of 0.65 fall under the permeability class "moderate" and mixes having w/c ratio of 0.40 fall under permeability class "low" as defined in ASTM 1260.

Similarly, performance of experimental mixes (containing water cooled ferrochrome slag as replacement of natural sand) in case of chloride migration test as per NT build 492 is similar and comparable to their corresponding control mixes. In case of accelerated carbonation test, mixes prepared at water to cement ratio of 0.65 (both experimental and control mix) showed similar carbonation depth (of around $8 \mathrm{~mm}$ ) and mixes prepared at water to cement ratio of 0.40 (both experimental and control mix) showed nil carbonation depth. Sulphate expansion results for all the concrete mixes are well within the maximum 
limits prescribed by ASTM C 1012. Sorptivity test results of experimental mixes containing water cooled ferrochrome slag as replacement of natural sand are similar and comparable to their corresponding control mixes.

This shows that replacement of natural fine aggregates with water cooled ferrochrome slag aggregates in a concrete mix does not have any negative or detrimental effect on the durability properties of concrete.

\subsection{Concrete Mixes Containing Air Cooled Ferrochrome Slag as Replacement of Natural Coarse Aggregate}

Along with two control concrete mixes (M4 and M0), mixes were prepared by replacing natural coarse aggregate with air cooled ferrochrome slag at 30,60 and 100\% along with $100 \%$ natural fine aggregates at both the water cement. Thus, six experimental mixes (containing air cooled Ferrochrome slag) were prepared along with two control mixes (M0 and M4). All the concrete mixes were designed for initial slump value of around $150 \mathrm{~mm}$. Mix design details of concrete mixes are tabulated in Table 11.

Table 11. Concrete mix design details of mixes containing air cooled ferrochrome slag as replacement of natural coarse aggregate

\begin{tabular}{llllll}
\hline & $\begin{array}{l}\text { Ferrochrom } \\
\text { e slag as } \\
\text { coarse } \\
\text { Mggregates } \\
(\%)\end{array}$ & $\begin{array}{l}\text { Cement } \\
(\mathrm{Kg} / \mathrm{m} 3)\end{array}$ & $\begin{array}{l}\text { Water } \\
\mathrm{Kg} / \mathrm{m} 3\end{array}$ & $\begin{array}{l}\text { Natural } \\
\text { Fine aggregate } \\
(\mathrm{Kg} / \mathrm{m} 3)\end{array}$ & $\begin{array}{l}\text { Ferrochrome } \\
\text { slag as coarse } \\
\text { Aggregate } \\
(10 \mathrm{~mm}) \\
(\mathrm{Kg} / \mathrm{m} 3)\end{array}$ \\
\hline M0 & 0 & 300 & 195 & 874 & 0 \\
M8 & 30 & 300 & 195 & 863 & 116 \\
M9 & 60 & 300 & 195 & 863 & 233 \\
M10 & 100 & 300 & 195 & 862 & 387 \\
M4 & 0 & 425 & 170 & 773 & 0 \\
M11 & 30 & 425 & 170 & 759 & 123 \\
M12 & 60 & 425 & 170 & 759 & 245 \\
M13 & 100 & 425 & 170 & 759 & 409 \\
\hline
\end{tabular}

Table 11. (Con.) Concrete mix design details of mixes containing air cooled ferrochrome slag as replacement of natural coarse aggregate

\begin{tabular}{ccccc}
\hline Mix & $\begin{array}{c}\text { Ferrochrome } \\
\text { slag as coarse } \\
\text { aggregates } \\
(20 \mathrm{~mm}) \\
(\mathrm{Kg} / \mathrm{m} 3)\end{array}$ & $\begin{array}{c}\text { Natural Coarse } \\
\text { Aggregate } \\
(10 \mathrm{~mm}) \\
(\mathrm{Kg} / \mathrm{m} 3)\end{array}$ & $\begin{array}{c}\text { Natural Coarse } \\
\text { Aggregate } \\
(20 \mathrm{~mm}) \\
(\mathrm{Kg} / \mathrm{m} 3)\end{array}$ & $\begin{array}{c}\text { Admix } \\
(\%)\end{array}$ \\
\hline M0 & 0 & 414 & 623 & 0 \\
M8 & 217 & 286 & 431 & 0 \\
M9 & 433 & 164 & 246 & 0 \\
M10 & 721 & 0 & 0 & 0.6 \\
M4 & 0 & 439 & 661 & 0.2 \\
M11 & 229 & 302 & 454 & 0.3 \\
M12 & 457 & 172 & 260 & 0.3 \\
M13 & 762 & 0 & 0 & 0.3 \\
\hline
\end{tabular}




\subsubsection{Fresh Concrete Properties}

Fresh concrete properties such as workability and air content were evaluated for all the 8 mixes. Test results are given in Table 12.

Table 12. Fresh Concrete properties of mixes containing air cooled ferrochrome slag as replacement of natural coarse aggregate

S. No W/c Ratio Mix ID $\begin{gathered}\text { Ferrochrome slag as } \\ \text { coarse Aggregates (\%) }\end{gathered} \quad \begin{gathered}\text { Natural coarse } \\ \text { aggregates }\end{gathered}$

\begin{tabular}{lcccc}
\hline 1 & 0.65 & M0 & 0 & 100 \\
2 & 0.65 & M8 & 30 & 70 \\
3 & 0.65 & M9 & 60 & 40 \\
4 & 0.65 & M10 & 100 & 0 \\
5 & 0.40 & M4 & 0 & 100 \\
6 & 0.4 & M11 & 30 & 70 \\
7 & 0.4 & M12 & 60 & 40 \\
8 & 0.4 & M13 & 100 & 0 \\
\hline
\end{tabular}

Table 12. (Con.) Fresh Concrete properties of mixes containing air cooled ferrochrome slag as replacement of natural coarse aggregate

\begin{tabular}{|c|c|c|c|c|c|c|}
\hline \multirow{2}{*}{ S. No } & \multicolumn{4}{|c|}{ Workability of concrete (mm): } & \multirow{2}{*}{$\begin{array}{c}\text { Air } \\
\text { Content, } \\
\% \\
\end{array}$} & \multirow{2}{*}{ Remarks } \\
\hline & 0 Min & $30 \mathrm{Min}$ & 60 Min & $120 \mathrm{Min}$ & & \\
\hline 1 & 145 & 135 & 125 & 100 & 1.8 & \multirow{3}{*}{$\begin{array}{l}\text { Homogeneous } \\
\text { mix }\end{array}$} \\
\hline 2 & 150 & 140 & 120 & 80 & 1.7 & \\
\hline 3 & 150 & 130 & 110 & 50 & 1.8 & \\
\hline 4 & 150 & 120 & 70 & 50 & 2 & $\begin{array}{l}\text { Segregation } \\
\text { and bleeding }\end{array}$ \\
\hline 5 & 150 & 140 & 120 & 90 & 1.7 & \multirow{3}{*}{$\begin{array}{l}\text { Homogeneous } \\
\text { mix }\end{array}$} \\
\hline 6 & 150 & 135 & 110 & 70 & 1.6 & \\
\hline 7 & 140 & 125 & 90 & 40 & 1.9 & \\
\hline 8 & 145 & 90 & 60 & 50 & 2.1 & $\begin{array}{l}\text { Segregation } \\
\text { and bleeding }\end{array}$ \\
\hline
\end{tabular}

Concrete mixes containing air cooled ferrochrome slag showed significantly higher slump loss after 60 and 120 minutes in comparison to the control concrete mixes. Air content of all 8 mixes were similar and comparable (around 2\%). It was observed that when replacement of natural coarse aggregate with air cooled ferrochrome slag goes beyond $60 \%$, mixes showed signs of segregation and bleeding due to high specific gravity of ferrochrome slag.

\subsubsection{Hardened Concrete Properties}

Hardened concrete properties were evaluated for all the six concrete mixes (M8 to M13) along with the control mixes (M4 and M0). Specimen size, test method and age of testing for all the tests were kept same as discussed in 4.1.2. Test results have been tabulated in Table 13. 
Table 13. Hardened concrete properties of mixes containing air cooled ferrochrome slag as replacement of natural coarse aggregate

\begin{tabular}{|c|c|c|c|c|c|c|c|c|}
\hline \multirow[b]{2}{*}{$\mathrm{W} / \mathrm{c}$} & \multirow[b]{2}{*}{ Mix ID } & \multirow{2}{*}{$\begin{array}{c}\text { Ferrochro } \\
\text { me slag as } \\
\text { coarse } \\
\text { Aggregates } \\
(\%)\end{array}$} & \multicolumn{4}{|c|}{ Compressive Strength, MPa } & \multicolumn{2}{|c|}{$\begin{array}{c}\text { Flex Strength, } \\
\mathrm{MPa}\end{array}$} \\
\hline & & & 1 Day & 3 Day & 7 Day & 28 Day & 7 Day & $\begin{array}{c}28 \\
\text { Day }\end{array}$ \\
\hline 0.65 & M0 & 0 & 4.54 & 12.5 & 18.1 & 26.22 & 4.07 & 5.05 \\
\hline 0.65 & M8 & 30 & 4.91 & 16.7 & 19.11 & 27.96 & 4 & 4.83 \\
\hline 0.65 & M9 & 60 & 3.61 & 9.93 & 16.01 & 24.69 & 3.87 & 4.73 \\
\hline 0.65 & M10 & 100 & 6.57 & 16.4 & 21.68 & 28.55 & 3.89 & 4.97 \\
\hline 0.4 & M4 & 0 & 15.95 & 32 & 41.86 & 49.79 & 6.4 & 8.07 \\
\hline 0.4 & M11 & 30 & 14.42 & 30.9 & 33.04 & 47.44 & 5.67 & 7.03 \\
\hline 0.4 & M12 & 60 & 9.58 & 29.6 & 38.19 & 45.44 & 5.87 & 7.7 \\
\hline 0.4 & M13 & 100 & 11.92 & 29.9 & 37.18 & 45.39 & 4.73 & 6.93 \\
\hline
\end{tabular}

Table 13. (Con.) Hardened concrete properties of mixes containing air cooled ferrochrome slag as replacement of natural coarse aggregate

\begin{tabular}{|c|c|c|c|c|c|}
\hline $\mathrm{W} / \mathrm{c}$ & Mix ID & $\begin{array}{c}\text { Split } \\
\text { Tensile } \\
\text { Strength, } \\
\mathrm{MPa}\end{array}$ & $\begin{array}{c}\text { Dry Density } \\
\mathrm{Kg} / \mathrm{m} 3\end{array}$ & $\begin{array}{c}\text { Drying } \\
\text { Shrinkage }\end{array}$ & $\begin{array}{c}\text { MOE } \\
(\mathrm{N} / \mathrm{mm} 2)\end{array}$ \\
\hline & & 28 Day & 28 days & 28 days & 28 Days \\
\hline 0.65 & M0 & 2.42 & 2450 & 0.0171 & 28204 \\
\hline 0.65 & M8 & 2.41 & 2470 & 0.0175 & 28508 \\
\hline 0.65 & M9 & 2.17 & 2460 & 0.0159 & 26588 \\
\hline 0.65 & M10 & 2.54 & 2580 & 0.0170 & 28486 \\
\hline 0.4 & M4 & 4.51 & 2478 & 0.0191 & 37144 \\
\hline 0.4 & M11 & 3.46 & 2490 & 0.0174 & 34140 \\
\hline 0.4 & M12 & 3.57 & 2515 & 0.0171 & 34395 \\
\hline 0.4 & M13 & 3.87 & 2560 & 0.0167 & 33854 \\
\hline
\end{tabular}

Compressive, flexural and split tensile strength at age of 28 days for experimental mixes (containing air cooled ferrochrome slag as replacement of coarse aggregates) at both $\mathrm{w} / \mathrm{c}$ were found to be similar and comparable to their control mix. Due to higher specific gravity of ferrochrome slag, dry density of the concrete mixes containing air cooled ferrochrome slag were higher than control mixes. The drying shrinkage values for all the concrete mixes were found satisfactory and comparable with their corresponding control mixes. Modulus of Elasticity (MOE) of the concrete mixes containing ferrochrome slag as replacement of natural coarse aggregates were found to be similar and comparable to corresponding control mixes.

\subsubsection{Durability Properties of Concrete Mixes}

Durability parameters of concrete such as Rapid Chloride ion penetrability test (RCPT) as per ASTM C-1202, Sulphate expansion test as per ASTM C-1012, Chloride migration test as per NT Build 492, accelerated carbonation test as per ISO 1920 part 12 and sorptivity test as per ASTM 1585 were evaluated for all the eight concrete mixes. Test results have been presented in Table 14. 
Table 14. Durability properties of concrete mixes containing air cooled ferrochrome slag as replacement of natural coarse aggregate

\begin{tabular}{|c|c|c|c|c|c|c|}
\hline \multirow[t]{2}{*}{$\mathrm{W} / \mathrm{c}$} & \multirow[t]{2}{*}{ Mix ID } & \multirow{2}{*}{$\begin{array}{c}\text { Ferrochrome } \\
\text { slag as coarse } \\
\text { Aggregates } \\
(\%)\end{array}$} & \multirow{2}{*}{$\begin{array}{c}\begin{array}{c}\text { RCPT, } \\
\text { Coulomb }\end{array} \\
28 \text { Day }\end{array}$} & \multicolumn{3}{|c|}{$\begin{array}{l}\text { Chloride Migration, NT Build } \\
\text { Diffusion coefficient (x 10-12 } \\
\mathrm{m} 2 / \mathrm{s} \text { ) }\end{array}$} \\
\hline & & & & 28 Day & 56 Day & 90 Day \\
\hline 0.65 & M0 & 0 & 3542 & 8.31 & 6.99 & 3.34 \\
\hline 0.65 & M8 & 30 & 2331 & 9.03 & 5.88 & 4.27 \\
\hline 0.65 & M9 & 60 & 3574 & 8.54 & 6.24 & 2.6 \\
\hline 0.65 & M10 & 100 & 4259 & 6.48 & 3.98 & 3.12 \\
\hline 0.4 & M4 & 0 & 1525 & 7.49 & 5.56 & 3.65 \\
\hline 0.4 & M11 & 30 & 2189 & 6.81 & 5.29 & 3.68 \\
\hline 0.4 & M12 & 60 & 3490 & 9 & 5.44 & 3.71 \\
\hline 0.4 & M13 & 100 & 2876 & 8.52 & 5.90 & 3.58 \\
\hline
\end{tabular}

Table 14. (Con.) Durability properties of concrete mixes containing air cooled ferrochrome slag as replacement of natural coarse aggregate

\begin{tabular}{cccccccc}
\hline \multirow{2}{*}{ W/c } & Mix & \multicolumn{2}{c}{ Sulphate expansion (\%) } & Carbonation & \multicolumn{2}{c}{ Sorptivity } \\
& ID & 28 Day & 56 Day & 90 Day & Depth, mm & Initial & Secondary \\
\hline 0.65 & M0 & 0.002 & 0.006 & 0.008 & 8.74 & 0.0057 & 0.0024 \\
0.65 & M8 & 0.001 & 0.004 & 0.007 & 7.65 & 0.0021 & 0.0010 \\
0.65 & M9 & 0.002 & 0.005 & 0.008 & 12.55 & 0.0033 & 0.0017 \\
0.65 & M10 & 0.003 & 0.005 & 0.009 & 10.55 & 0.0023 & 0.0013 \\
0.4 & M4 & 0.003 & 0.006 & 0.009 & Nil & 0.0032 & 0.0008 \\
0.4 & M11 & 0.004 & 0.006 & 0.008 & Nil & 0.0011 & 0.0004 \\
0.4 & M12 & 0.003 & 0.005 & 0.008 & Nil & 0.0010 & 0.0003 \\
0.4 & M13 & 0.005 & 0.007 & 0.009 & Nil & 0.0013 & 0.0004 \\
\hline
\end{tabular}

In case of RCPT results, it was observed that experimental mixes containing water cooled ferrochrome slag as replacement of natural sand show comparable performance to corresponding control concrete mixes. Similarly, performance of experimental mixes (containing air cooled ferrochrome slag as replacement of natural coarse aggregates) in case of chloride migration test as per NT build 492 is similar and comparable to their corresponding control mixes. In case of accelerated carbonation test, mixes prepared at water to cement ratio of 0.65 (both experimental and control mix) showed similar carbonation depth (of around 8 to $12 \mathrm{~mm}$ ) and mixes prepared at water to cement ratio of 0.40 (both experimental and control mix) showed nil carbonation depth. Sulphate expansion results for all the concrete mixes are well within the maximum limits prescribed by ASTM C 1012. Sorptivity test results of experimental mixes containing air cooled ferrochrome slag as replacement of natural coarse aggregates are similar and comparable to their corresponding control mixes.

This shows that replacement of natural coarse aggregates with air cooled ferrochrome slag aggregates in a concrete mix does not have any negative or detrimental effect on the durability properties of concrete.

\subsection{Leaching Studies on Selected Concrete Mixes}

Leaching study was also conducted on few selected concrete samples made with replacement of natural aggregates with corresponding ferrochrome slag aggregates, as per Toxicity Characteristic Leaching Procedure (TCLP) to detect the presence of different 
heavy metals constituents. The results of concentration of heavy metals ions leached out from concrete samples are given in Table 15.

Table 15. Results of Leaching study on concrete samples

\begin{tabular}{|c|c|c|c|c|c|c|c|}
\hline $\begin{array}{c}\text { Sl } \\
\text { No. }\end{array}$ & Constituents & M0 & M4 & M1 & M5 & M6 & $\begin{array}{c}\text { Limits as per } \\
\text { TCLP } \\
\text { procedure }\end{array}$ \\
\hline 1 & Chromium (Cr) & 0.1341 & 0.010 & 0.119 & 0.169 & 0.187 & 5 \\
\hline 2 & Copper (Cu) & 0.009 & 0.006 & 0.047 & 0.12 & 0.007 & 25 \\
\hline 3 & $\begin{array}{l}\text { Manganese } \\
(\mathrm{Mn})\end{array}$ & 0.002 & 0.002 & 0.025 & 0.002 & 0.002 & 10 \\
\hline 4 & Nickel (Ni) & 0.013 & BDL & 0.023 & 0.007 & BDL & 20 \\
\hline 5 & Lead $(\mathrm{Pb})$ & BDL & BDL & $\mathrm{BDL}$ & BDL & BDL & 5 \\
\hline 6 & Zinc (Zn) & 0.039 & 0.035 & 0.053 & 0.028 & 0.034 & 250 \\
\hline 7 & $(\mathrm{Fe})$ Iron & BDL & 0.048 & 0.032 & 0.010 & 0.001 & - \\
\hline 8 & Titanium (Ti) & 0.054 & 0.003 & 0.92 & 0.028 & 0.053 & - \\
\hline
\end{tabular}

As per the leachable concentration limits given by ministry of environment, forest and climate change guidelines, the observed values of heavy metal ions are lower than the prescribed limits.

\section{Conclusions}

Based on the results and observations of above mentioned studies following conclusions are drawn:

- Physical properties of water and air cooled ferrochrome slag meets the various requirements of IS: 383-2016. Specific gravity of slag samples was observed to be higher than that of natural aggregates. Water absorption and material finer than $75 \mu \mathrm{m}$ were found to be comparable with natural aggregates. The low values of abrasion, crushing and impact reflects the stronger nature of air cooled ferrochrome slag.

- The results of elemental analysis of ferrochrome slag samples showed that concentrations of elements are within limits.

- Concrete mixes were prepared at two w/c ratios by replacing natural fine aggregates with water cooled ferrochrome slag and natural coarse aggregates with air cooled ferrochrome slag. Concrete mixes containing Ferrochrome slag showed significantly higher slump loss after 60 and 120 minutes in comparison to the control mixes. It was observed that when replacement of natural aggregates with ferrochrome slag goes beyond $60 \%$, mixes showed signs of segregation and bleeding due to high specific gravity of ferrochrome slag. Hardened properties of concrete mixes containing ferrochrome slag were found to be higher or comparable to their corresponding control mixes at the age of 28 days. In terms of different durability related parameters, experimental mixes containing ferrochrome slag aggregates showed comparable performance in comparison to their corresponding control concrete mixes containing $100 \%$ natural aggregates.

- Leaching study was conducted on water and air cooled Ferrochrome slag as per Toxicity Characteristic Leaching Procedure (TCLP) to detect the presence of different heavy metals constituents such as $\mathrm{Cr}, \mathrm{Fe}, \mathrm{Zn}, \mathrm{Cu}, \mathrm{Mn}, \mathrm{Ni}, \mathrm{Pb}$ and $\mathrm{Ti}$. The observed values of heavy metal ions are lower than the prescribed limits. Leaching study was also conducted on few selected concrete samples made with replacement of natural aggregates with corresponding ferrochrome slag aggregates and the observed values of heavy metal ions are lower than the prescribed limits. 
Based on the above conclusions, following recommendations are being made:

Water cooled Ferrochrome slag can be used as replacement of natural fine aggregate up to $60 \%$ by weight along with $100 \%$ with natural coarse aggregates for making concrete. Air cooled Ferrochrome slag can be used as replacement of natural coarse aggregate up to $60 \%$ by weight along $100 \%$ with natural fine aggregates for making concrete.

\section{References}

[1] Panda CR, Mishra KK, Panda KC, Nayak BD, Nayak BB. 'Environmental and technical assessment of ferrochrome slag as concrete aggregate material, Construction and Building Materials, 49, 2013. https://doi.org/10.1016/j.conbuildmat.2013.08.002

[2] Sahu N, Biswas A, Kapure GU, A short review on utilization of ferrochromium slag, Mineral Processing and Extractive Metallurgy Review, 2016. https://doi.org/10.1080/08827508.2016.1168415

[3] Lind BB, Fallman AM, Larsson LB. Environmental impact of ferrochrome slag in road construction, International Conference on the Science and Engineering of Recycling for Environmental Protection, 2001. https://doi.org/10.1016/S0956-053X(00)00098-2

[4] Khalifa J, "Research on the use of Ferro-Chrome slag in civil engineering applications." MATEC Web of Conferences, 2018.

[5] Panda CR, Mishra KK, Panda KC, Nayak BD, Nayak BB. Environmental and technical assessment of ferrochrome slag as concrete aggregate material, Construction and Building Materials, 2013. https://doi.org/10.1016/i.conbuildmat.2013.08.002

[6] Sathwik SR, Sanjith J, Sudhakar GN. Development of high strength concrete using ferrochrome slag aggregate as replacement to coarse aggregate, American Journal of Engineering Research, 2016.

[7] Zyranov FA, Bukreev AB, Zyranova 00. Heavy Concrete on Cement with slag of low carbon ferrochrome. Electric Journal of Structural Engineering, 2016,

[8] IS: 2386 - 1963 (Reaffirmed 2002). "Methods of Test for Aggregates for Concrete”. BIS, New Delhi

[9] IS 4032 -1995. "Method of chemical analysis of hydraulic cement". BIS, New Delhi

[10] ASTM D5233 - 92 (2009). "Standard Test Method for Single Batch Extraction Method for Wastes". ASTM International, West Conshohocken, PA

[11] IS: 1199 -1959 (Reaffirmed 2004). "Methods of Sampling and Analysis of Concrete". BIS, New Delhi

[12] IS: 383-2016. "Coarse and Fine Aggregate for Concrete - Specification (Third Revision)". BIS, New Delhi

[13] Government of India, Ministry of Environment, Forest and Climate Change, published in the gazette of India, extraordinary, part II, section 3, sub-section (i)

[14] ASTM C1260-14. "Standard Test Method for Potential Alkali Reactivity of Aggregates (Mortar-Bar Method)". ASTM International, West Conshohocken, PA

[15] IS: 516 - 1959 (Reaffirmed 2004). "Methods of test of strength of concrete". BIS, New Delhi

[16] IS: 5816 - 1999 (Reaffirmed 2004), Splitting Tensile Strength of Concrete - Method of Test". BIS, New Delhi.

[17] ASTM C1202-19. "Standard Test Method for Electrical Indication of Concrete's Ability to Resist Chloride Ion Penetration" ASTM International, West Conshohocken, PA

[18] ASTM C1012. "Standard Test Method for Length Change of Hydraulic-Cement Mortars Exposed to a Sulfate Solution". ASTM International, West Conshohocken, PA

[19] NT BUILD 492 (1999). "Concrete, mortar and cement based repair materials: Chloride migration coefficient from non-steady-state migration experiments". Published by Nordtest, ISSN 0283-7153

[20] ISO 1920 Part 12 (2015). "Determination of Carbonation resistance of concrete". 
[21] ASTM C1585-13. "Standard Test method for mesurement of rate of absorption of water by hydraulic cement concrete". ASTM International, West Conshohocken, PA. 